\title{
Review Article \\ Exercise and Physical Activity in the Therapy of Substance Use Disorders
}

\author{
Elisabeth Zschucke, Andreas Heinz, and Andreas Ströhle \\ Klinik für Psychiatrie und Psychotherapie, Charité-Universitätsmedizin Berlin, Charité Campus Mitte, Charitéplatz 1, \\ 101117 Berlin, Germany
}

Correspondence should be addressed to Elisabeth Zschucke, elisabeth.zschucke@charite.de

Received 31 October 2011; Accepted 8 December 2011

Academic Editor: Eckart Ruther

Copyright ( 92012 Elisabeth Zschucke et al. This is an open access article distributed under the Creative Commons Attribution License, which permits unrestricted use, distribution, and reproduction in any medium, provided the original work is properly cited.

\begin{abstract}
Exercise and physical activity are constantly gaining attention as adjuvant treatment for substance use disorders, supplementing classical pharmacological and psychotherapeutic approaches. The present work reviews studies addressing the therapeutic effects of exercise in alcohol abuse/dependence, nicotine abuse/dependence, and illicit drug abuse/dependence. In the field of smoking cessation, evidence is strong for exercise as an effective adjuvant treatment, whereas no generalizable and methodologically strong studies have been published for alcohol and drug treatment so far, allowing only preliminary conclusions about the effectiveness of exercise in these disorders. A couple of potential mechanisms are discussed, by which exercise may act as an effective treatment, as well as future directions for studies investigating exercise as a treatment strategy for substance use disorders.
\end{abstract}

\section{Introduction}

Substance use disorders (SUDs), both abuse and dependence, are a common mental health problem with 12-month prevalences ranging from 3.8 to $5.6 \%$ [1], causing immense social and economic costs due to physical, psychological, and social comorbidities and consequences (rank 5 of disabilityadjusted life years (DALYs) in the European Union, see [1]).

Despite increasingly effective psychopharmacologic and psychotherapeutic intervention strategies, relapse rates are commonly high, resulting in a need for adjuvant therapies that help maintaining abstinence and target physical conditions related to the SUD.

1.1. Exercise as Preventive and Therapeutic Intervention. In several cross-sectional studies, levels of exercise (EX) and physical activity (PA) were found to be negatively associated with different mental disorders (e.g., [2]), and higher levels of PA were longitudinally associated with lower onsets of mental disorders [3]. SUDs (alcohol dependence, nicotine dependence, and any SUD) were shown to be less prevalent in physically active subjects [3], and one longitudinal study reported a preventive action of regular PA with regard to alcohol intoxications, alcohol-related problems, and drug use [4].
Additionally, many studies have demonstrated therapeutic effects of EX interventions in other mental disorders, especially depression and anxiety disorders [5-8]. PA and EX may also help to reduce chronic physical conditions which are frequent in patients with mental disorders, especially SUD $[9,10]$.

This paper aims at subsuming empirical evidence for therapeutic effects of PA and EX in SUD and arriving at conclusions concerning further research and clinical practice.

\section{Methods}

The databases PubMed, Medline, and Web of Science were searched for studies in English or German published between 1970 and 2011 which had investigated any form of EX as therapeutic intervention strategy. Search terms included "exercise," "physical activity," "substance use disorder," "dependence," "abuse," "illicit drugs," "alcohol," "nicotine," "cannabis," "opiate," "stimulant," and "cocaine," in the respective languages.

The bibliographies of all retrieved articles were searched for additional references.

Studies exclusively focusing on exercise as a prevention strategy were excluded. 
For nicotine abuse and dependence, only randomizedcontrolled trials (RCTs) were included into this paper. Since the literature was very limited concerning RCTs on alcohol abuse/dependence and illicit drug abuse/dependence, studies with inadequate control strategies and small samples were also included into this paper.

\section{Results}

In the following sections, studies will be reviewed separately for different SUDs, due to the heterogeneity concerning study designs, methods, and results.

3.1. Nicotine Abuse and Dependence. Smoking is very prevalent both in the general population and as a comorbid substance use disorder [45]. Unassisted smoking cessation attempts are mostly unsuccessful, with success rates ranging from 3 to $5 \%$ in the $6-12$-month followup [46]. Success rates can be increased by behavioral therapy, nicotine replacement therapy (NRT), and medication (e.g., bupropion and varenicline) [47].

Since a large number of studies investigated the effects of exercise during and after smoking cessation, only RCTs are listed in Table 1.

Seventeen RCTs were identified. Fourteen of these trials $[11,12,14-16,18-26]$ studied otherwise healthy subjects, one included patients after acute myocardial infarction [13], another one studied depressed patients [27], and one trial investigated smoking cessation in abstinent alcoholdependent subjects [17]. Purely female samples were studied in 11 trials $[12,14,16,18,19,21-24,26,27]$, purely male samples in one trial [13], and mixed samples in five trials $[11,15,17,20,25]$. The durations of EX interventions ranged from 5 to 26 weeks, and four studies used EX counseling instead of EX interventions [17, 20, 25, 27].

EX interventions were either compared to a standard intervention without EX component $[11,13,14,23]$, to CBT [22], to medication and/or NRT $[15,17,25]$, or to a contact control intervention [12, 16, 18-21, 24, 26, 27], and all studies reported smoking-related outcomes such as cigarette craving, withdrawal symptoms, and abstinence and relapse rates, respectively. Compared to a standard intervention, EX was found to improve one or multiple smoking-related outcomes in all four studies. When compared to CBT, EX was found to be as effective concerning abstinence rates (and especially effective when combined with NRT). Two studies reported similar effects for EX and medication/NRT $[15,25]$, whereas one study [17] found EX augmentation of CBT to be superior to NRT augmentation at posttreatment and similarly effective at 1-year followup. Comparing EX to a control intervention, three studies did not find positive effects of EX on smoking-related outcomes [12, 21, 27], three studies reported a trend towards positive EX effects $[16,24,26]$, and two found positive EX effects $[18,20]$.

Evidence is also mixed for secondary outcomes like depression, tension, stress, anxiety, and so forth. on the one hand, and weight gain on the other hand. Concerning emotional changes, two studies reported positive acute or long-term changes $[19,20]$, two studies did not find EXinduced improvements [26, 27], and one study found even higher tension and anxiety in the EX group at one followup time point [12]. Smoking cessation-related weight gain was lower in the EX condition of three studies [18, 22, 23] and higher in one study [27], while three studies [20, 21, 26] reported similar weight gain in EX and control conditions $[20,21,26]$.

Taken together, evidence is mixed, but some preliminary conclusions can be drawn concerning favorable effects of EX intervention in smoking cessation. First, EX intervention shows the clearest effects when compared to standard treatment, which becomes more unequivocal, when EX is compared to control groups which offer a similar amount of social support, therapeutic contact, and preoccupation with health-related topics. Second, the majority of studies have shown that EX interventions are as effective as other standard interventions for smoking cessation, such as CBT or $\mathrm{NRT} /$ medication. The intensity and frequency of training may be a key point: studies using $\geq 3$ training sessions per week (e.g., $[14,16,18,21,22])$ were likely to find fitness gains in the EX group, whereas 1-2 times per week seem not to be sufficient to achieve fitness gains [24]. Although objective assessment of fitness changes were not performed in all studies, five studies that reported fitness gains also reported favorable smoking outcomes $[11,13,14,16,18]$ compared to three which did not $[21,22,25]$, one study reported positive smoking outcomes despite identical increases of fitness in all groups [24], and two studies found neither fitness increases nor favorable smoking outcomes [12, 27].

Importantly, three studies concluded that EX adherence rather than the admission to an EX intervention per se predicted smoking abstinence $[15,21,25,26]$, suggesting an important role of motivation, individual resources, and selfefficacy.

One crucial aspect lies in the moment of implementation of the EX program: one study demonstrated that patients may be overstrained and react with negative effect, when smoking cessation and the EX intervention are realized simultaneously [47]. The implementation of EX a couple of weeks prior to the quit date may be advisable for another reason: EX can serve as a skill to acutely reduce withdrawal and craving symptoms.

A couple of studies addressed this issue (see $[48,49]$ for a review). In most cases, temporarily abstinent smokers were compared after a short bout of EX versus a control condition (e.g., passive waiting or video). Compared to the control conditions, EX was found to

(i) reduce the desire to smoke (effect sizes 0.53-2.2 during and after EX, and 0.14-0.74 at the latest follow-up time point);

(ii) reduce withdrawal symptoms (stress, anxiety, tension, irritability, restlessness) and negative mood;

(iii) reduce the anticipation of smoking being rewarding and pleasurable;

(iv) increase the latency period until the next cigarette (effect size 0.85-1.20). 


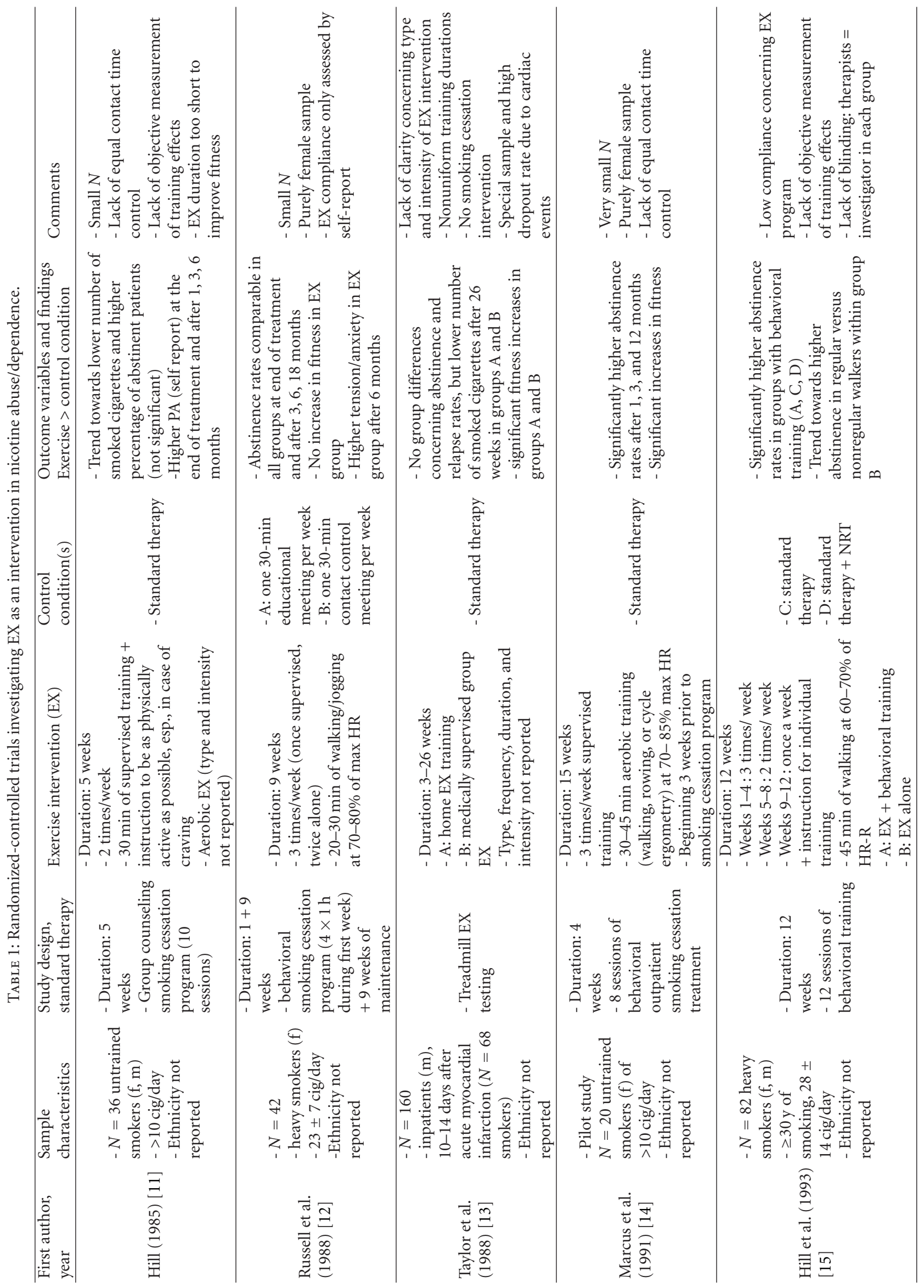




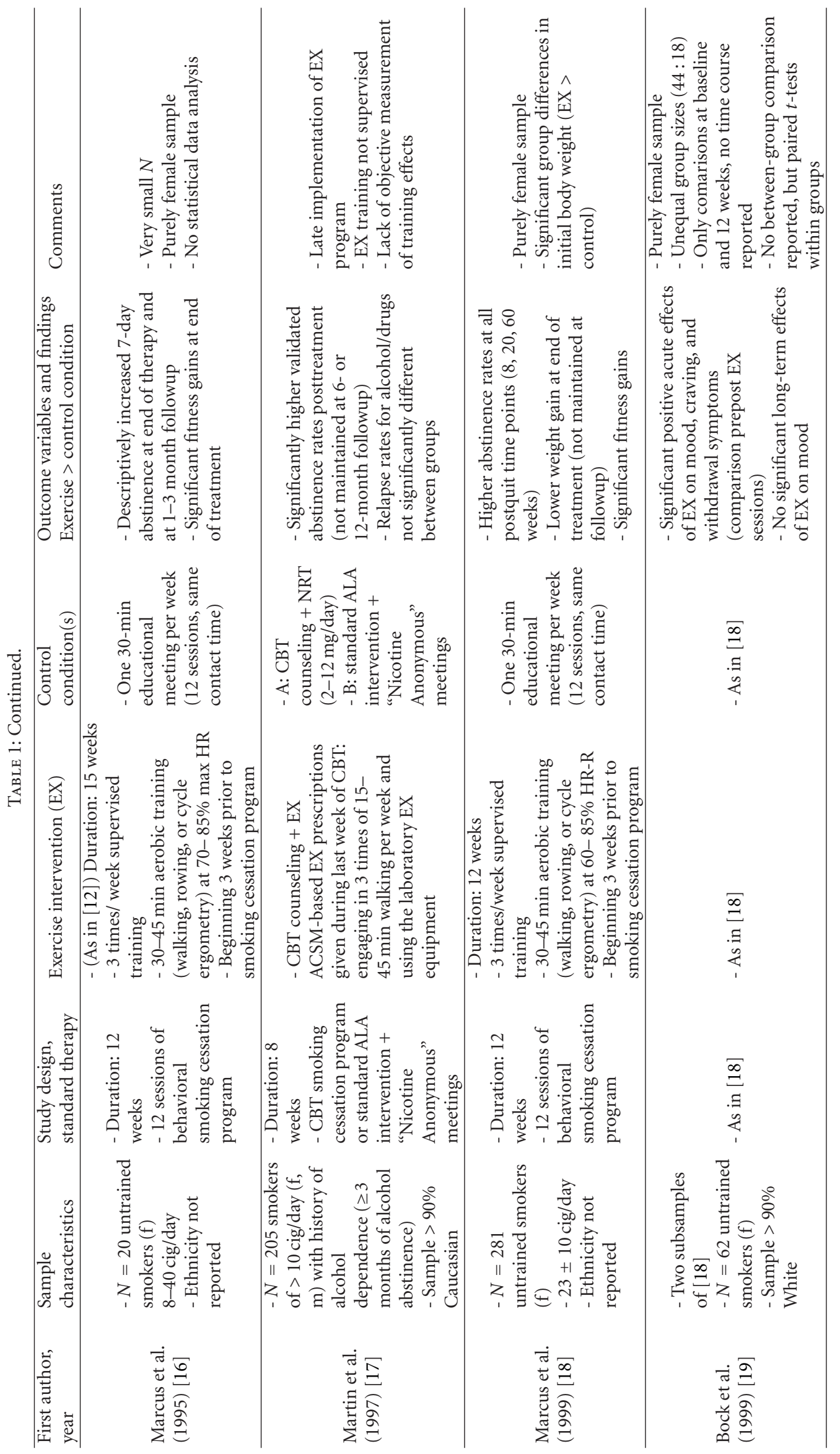




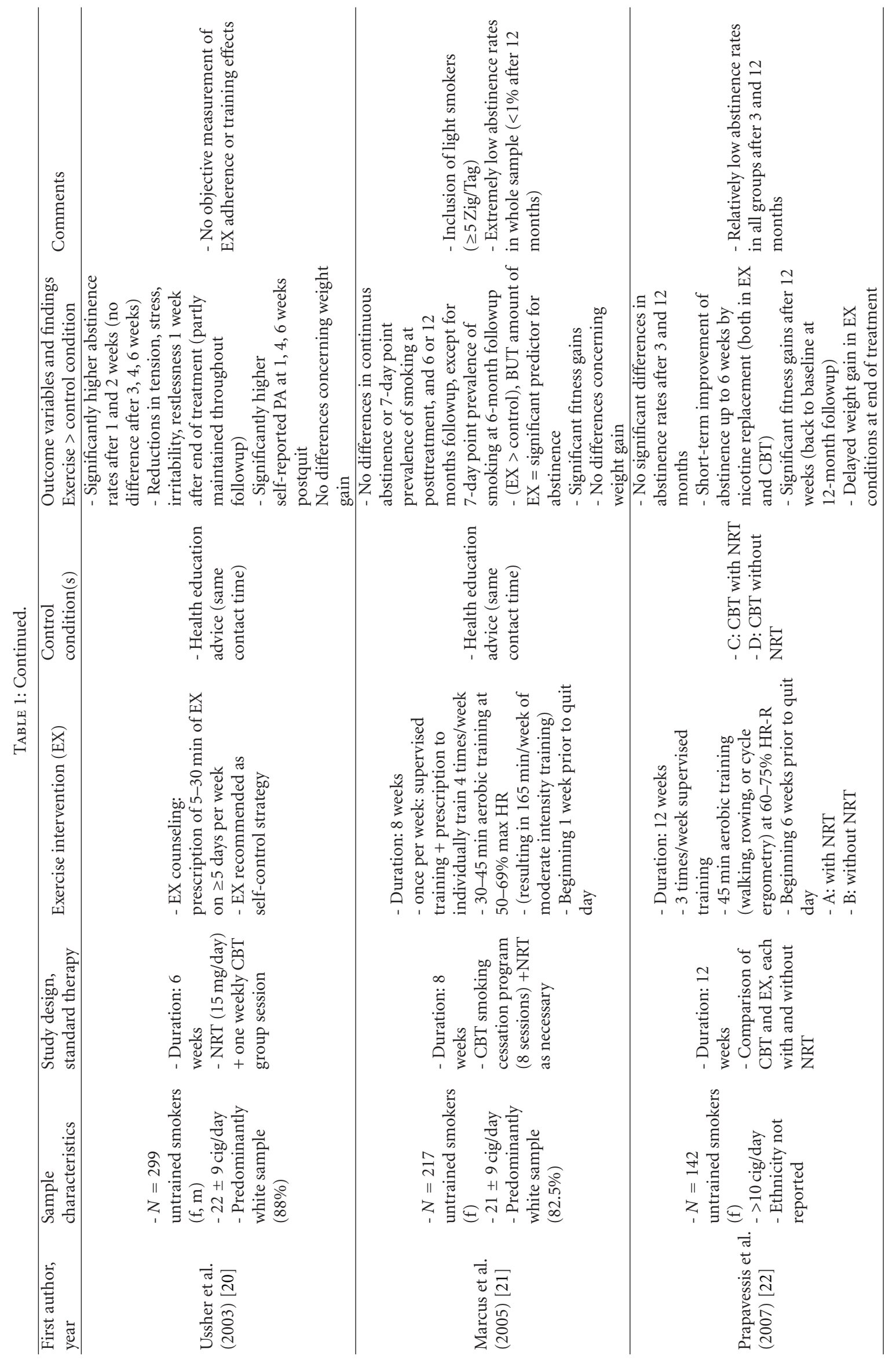




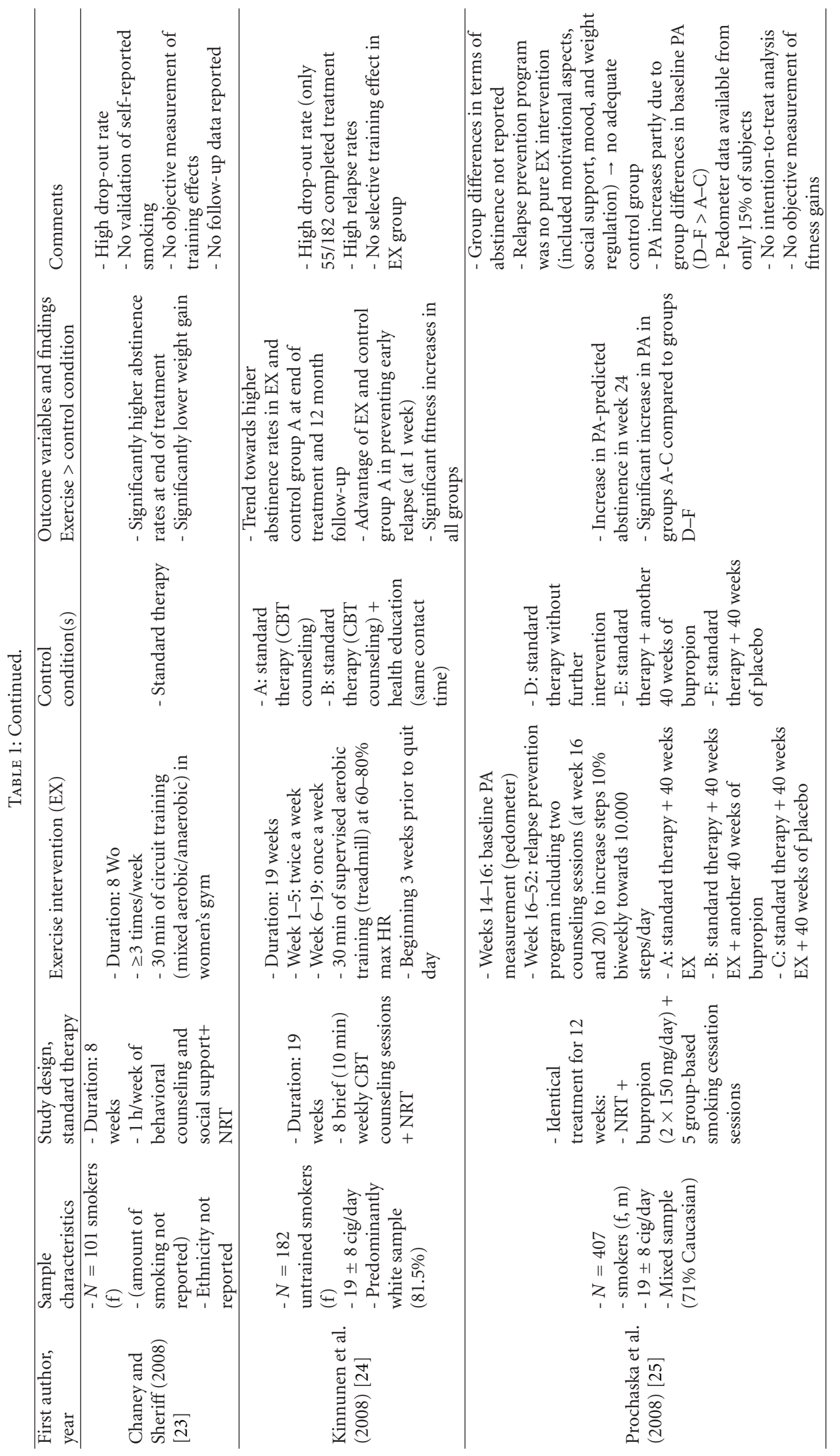




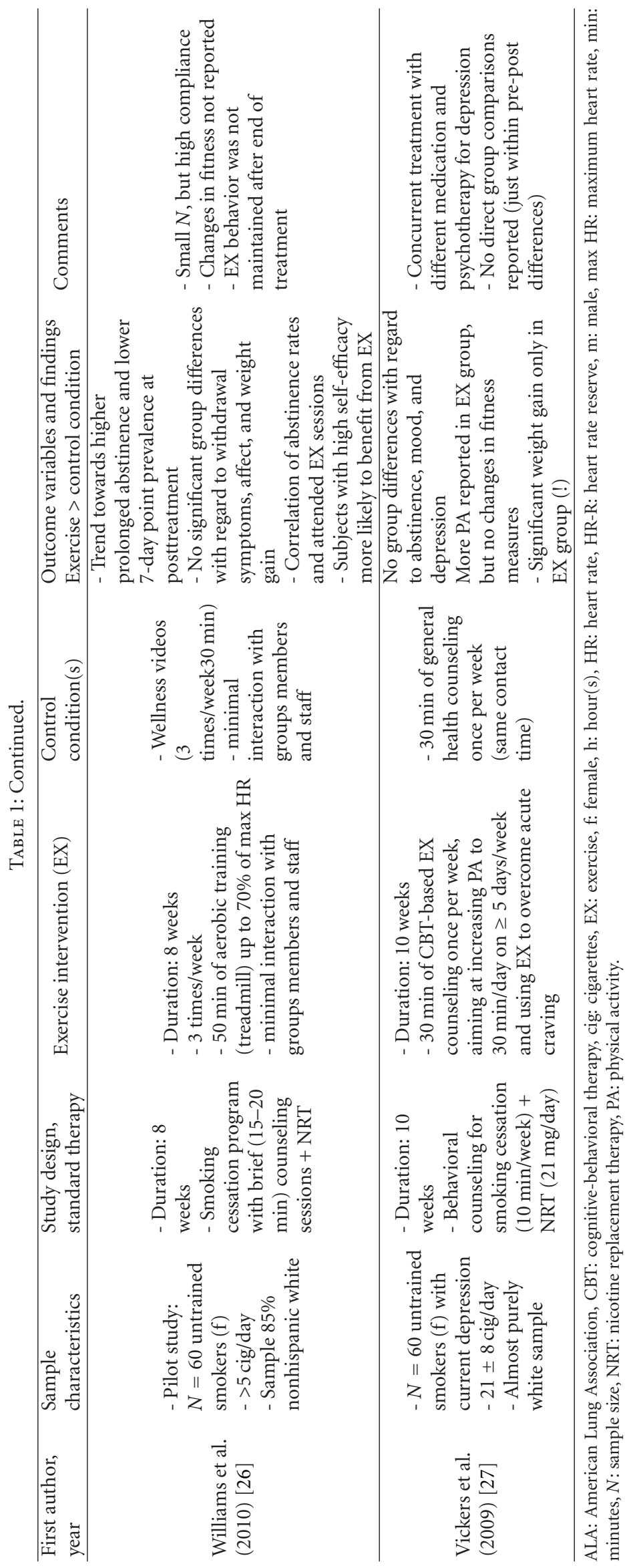


The acute EX interventions ranged from $5 \mathrm{~min}$ of isotonic muscle contraction to a brisk one-mile walk. Effects generally appeared very quickly (faster than with oral NRT), lasted between 5 and $50 \mathrm{~min}$, and were not solely explained by distraction, as controlled by different control conditions.

3.2. Alcohol. For the postacute alcohol treatment phase following detoxication, several psychotherapeutic interventions have proven effectiveness, for example, brief interventions (including psychoeducation, motivational interviewing and counseling), and cognitive-behavioral interventions (including cue exposure, self-management strategies, and coping skills) [50].

Furthermore, psychopharmacological treatment with acamprosate or naltrexone significantly increases abstinence rates on the long run [51].

However, the rates of relapse and physical and mental comorbidities are rather high, pointing out the need for adjuvant therapies and long-term life-style modifications.

Compared to smoking, evidence is more limited in alcohol abuse/dependence, and RCTs are extremely rare. Nine studies were identified that investigated the effects of EX programs on abstinence, relapse rates, and/or different associated somatic, emotional, and psychological outcomes (see Table 2).

In these studies, treatment duration ranged from four weeks [28, 33] to four months [31], with training frequencies ranging from three to five times a week. EX interventions were mostly aerobic [28-34, 36], but one study [35] used a holistic "Body-Mind" intervention which prohibits conclusions about EX alone.

Six studies reported drinking episodes, craving, or days of abstinence as substance-related outcomes [28, 30, 32, 34$36]$, and four of these studies found significantly stronger improvements in the EX group [30, 32, 35, 36], whereas two studies did not find any group differences $[28,34]$. Secondary psychological outcomes like depression, anxiety, stress, selfconcept, locus of control, and sleep quality, which increased at least in one of the EX conditions, were reported in four studies $[28,29,31,33]$. In contrast, two studies did not find group differences concerning the reduction of depression $[34,35]$ and anxiety [34].

Significant increases in fitness were reported in eight studies [28-32, 34-36], which were preserved at 5-month followup in one study [34], whereas one other study [33] did not find significant changes in fitness.

Only one study fulfilled criteria for a RCT [34], whereas the other studies had several methodological limitations. Seven studies included control groups [28, 30-35], whereas one study was a one-group pre-post comparison [29], and one study [36] did not employ control conditions at all. Random assignment of study participants to a treatment condition was performed in four studies [28, 31, 32, 34], whereas one study used a time-staggered control group [33], another study compared samples from different centers [30], and one study did not state their assignment strategy [35].

Sample sizes were small in five studies $[28,31-33,36]$, and none of the studies performed intention-to-treat analyses to correct for the high number of dropouts. Four studies did not specify the patients' diagnoses [30, 33, 34] or included subjects without a clinical diagnosis of alcohol abuse or dependence [32].

In summary, so far, there is only limited evidence for the efficacy of EX interventions in alcohol rehabilitation. Most cited studies must be interpreted cautiously due to methodological limitations. However, it can be stated that three [34] or four [33] weeks of supervised EX may not be sufficient to induce significant additional changes in anxiety, depression, and abstinence rates and that fitness gains are neither necessary nor sufficient to account for the behavioral and emotional changes reported in most studies.

One possible mechanism of action which is often hypothesized regarding the effects of EX is craving reduction. One study [52] investigated the acute effects of EX in detoxified patients, using a crossover design with $10 \mathrm{~min}$ of either moderate or light aerobic EX on a bicycle ergometer. During moderate EX, significant reductions of craving were observed. However, this effect did not continue after the end of the intervention, and there was a trend towards higher baseline levels of craving in the moderate EX condition. Therefore, the craving-reducing activity of EX remains subject to further studies.

An additional study gives information about exercise attitudes and behaviors in a sample of day-clinic patients [53]. Generally, 75\% of patients were interested in EX programs, and almost half of the patients stated to exercise regularly (preferably walking, weight lifting, and cycling). EX was appreciated for providing tension relief, stress reduction, and a more positive attitude. Barriers named by the patients included high costs, lack of motivation, time, knowledge, confidence and physical disability.

Hence, adequately powered RCTs are necessary to confirm or disprove beneficial effects of EX interventions in alcohol use disorders, and to disentangle potential mechanisms of action.

3.3. Illicit Substance Abuse/Dependence. Besides substitution therapy, established therapies for illicit drug abuse/ dependence include medication for relapse prevention (e.g., naltrexone) as well as different psychotherapeutic approaches (motivational interviewing, CBT, psychodynamic and systemic approaches, psychoeducation, and social therapy).

So far, no studies satisfying RCT-criteria have been published for this specific population. However, eight studies were identified which investigated therapeutic effects of EX in drug-dependent patients (see Table 3).

In these studies, treatment duration ranges from to two weeks [44] to six months [42], with training frequencies ranging from several times a day [41] to twice a week [40].

Six studies reported substance-related outcomes like craving, percentage of abstinent subjects, continuous days of abstinence [37, 38, 41-44], which improved with treatment in all six studies. Secondary psychological and social outcomes like depression, anxiety, tension, self-concept, locus of control, employment, and dwelling were reported in five studies [37-39, 41, 42], which generally increased at least in one of the EX conditions. 


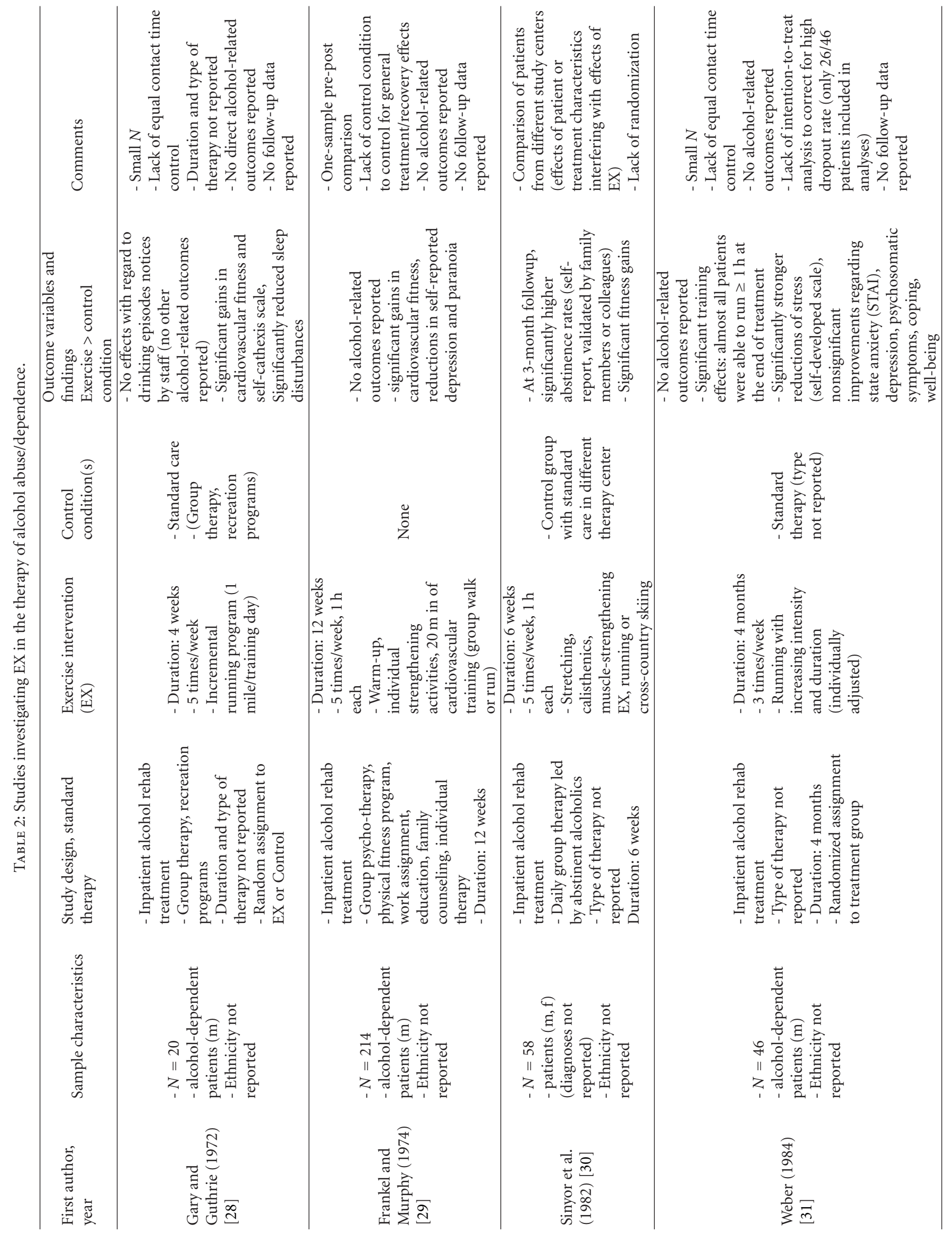




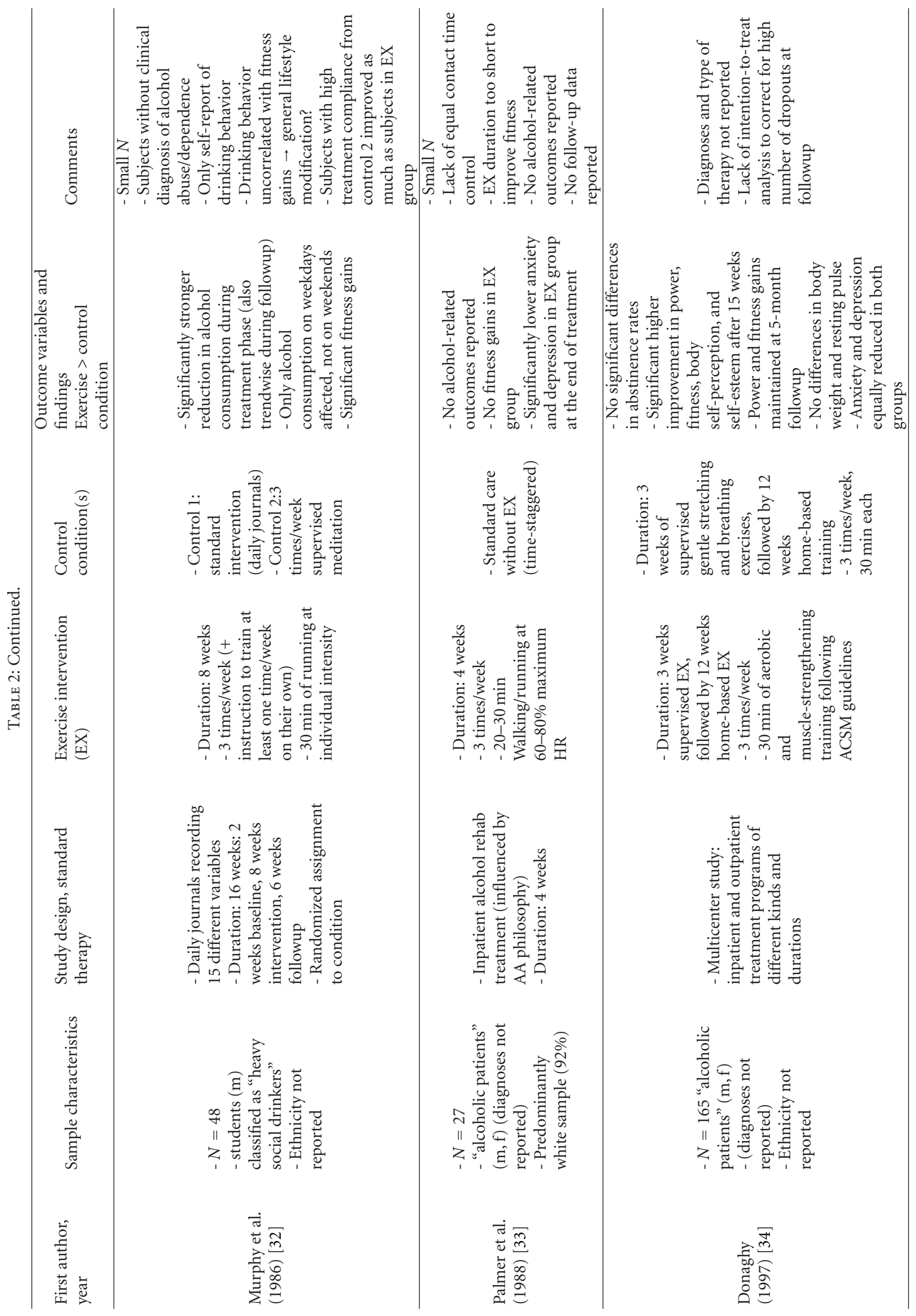




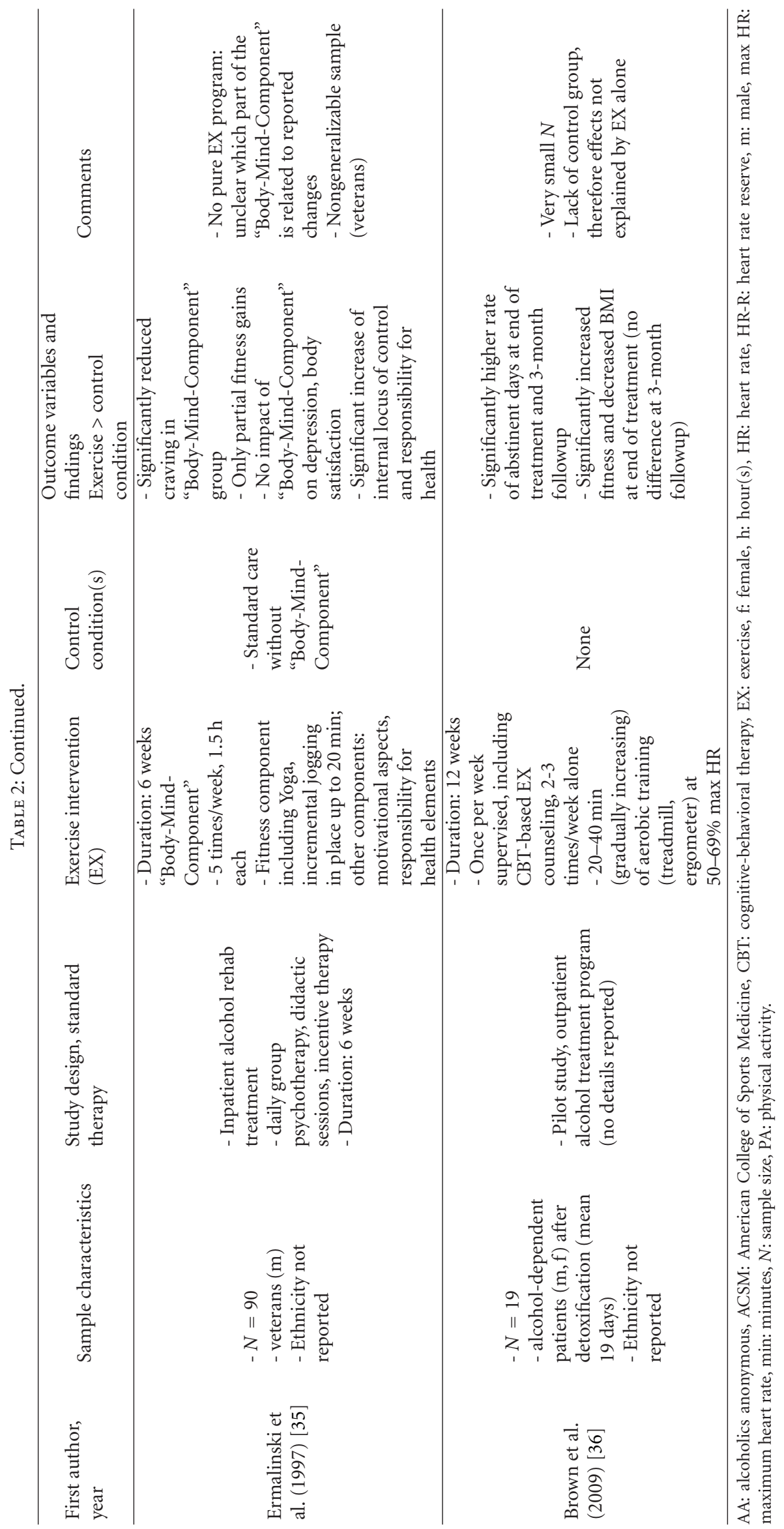




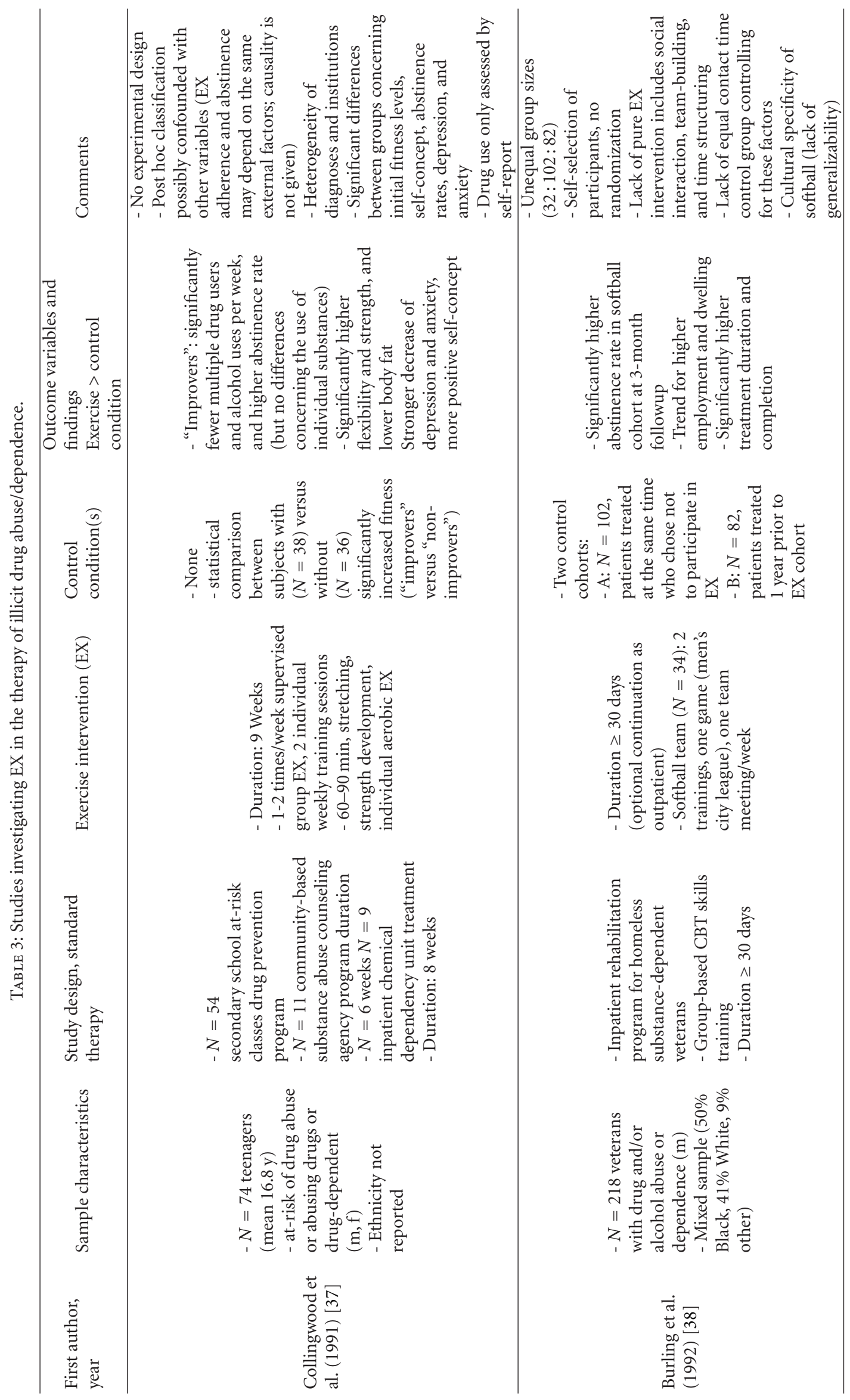




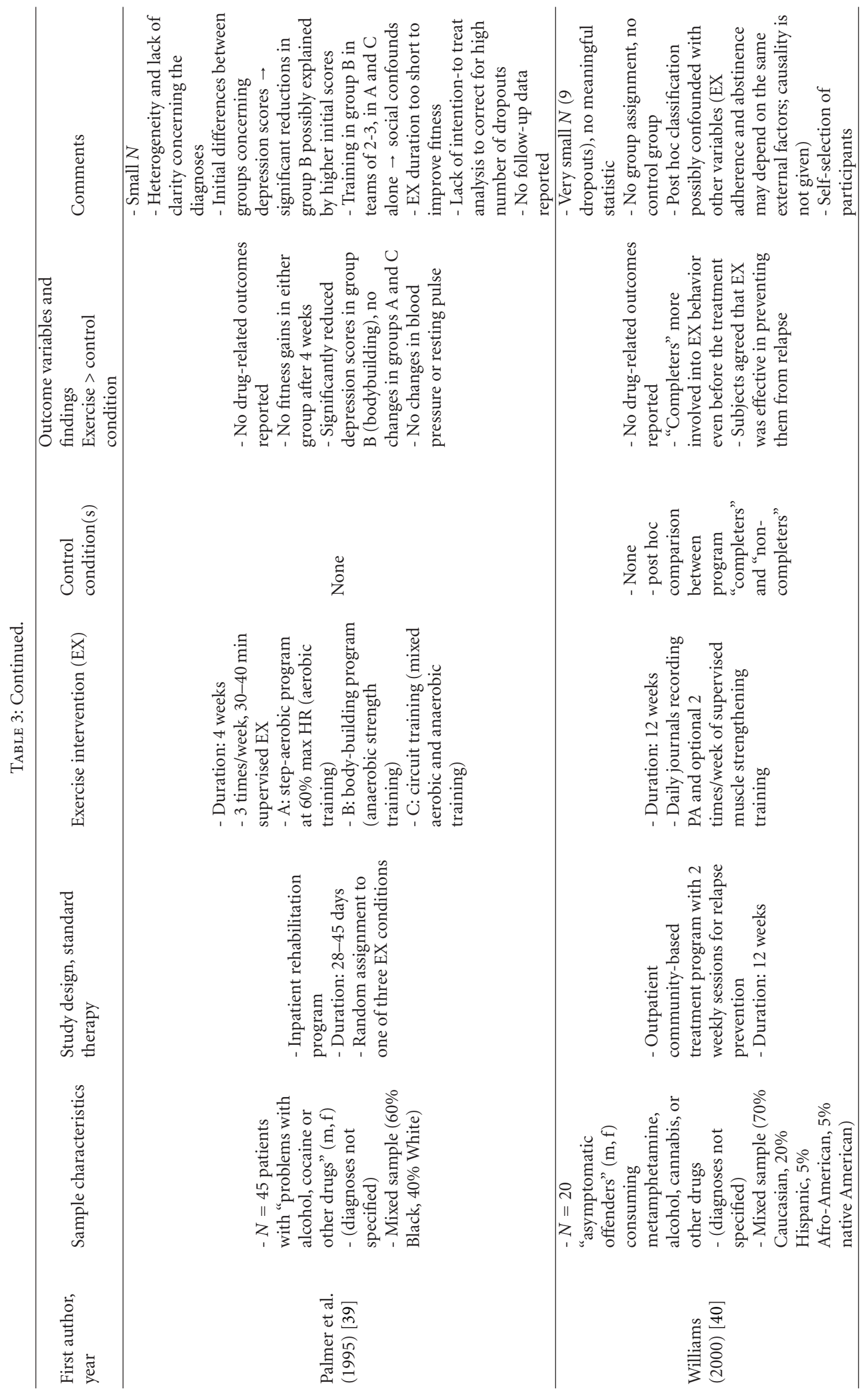




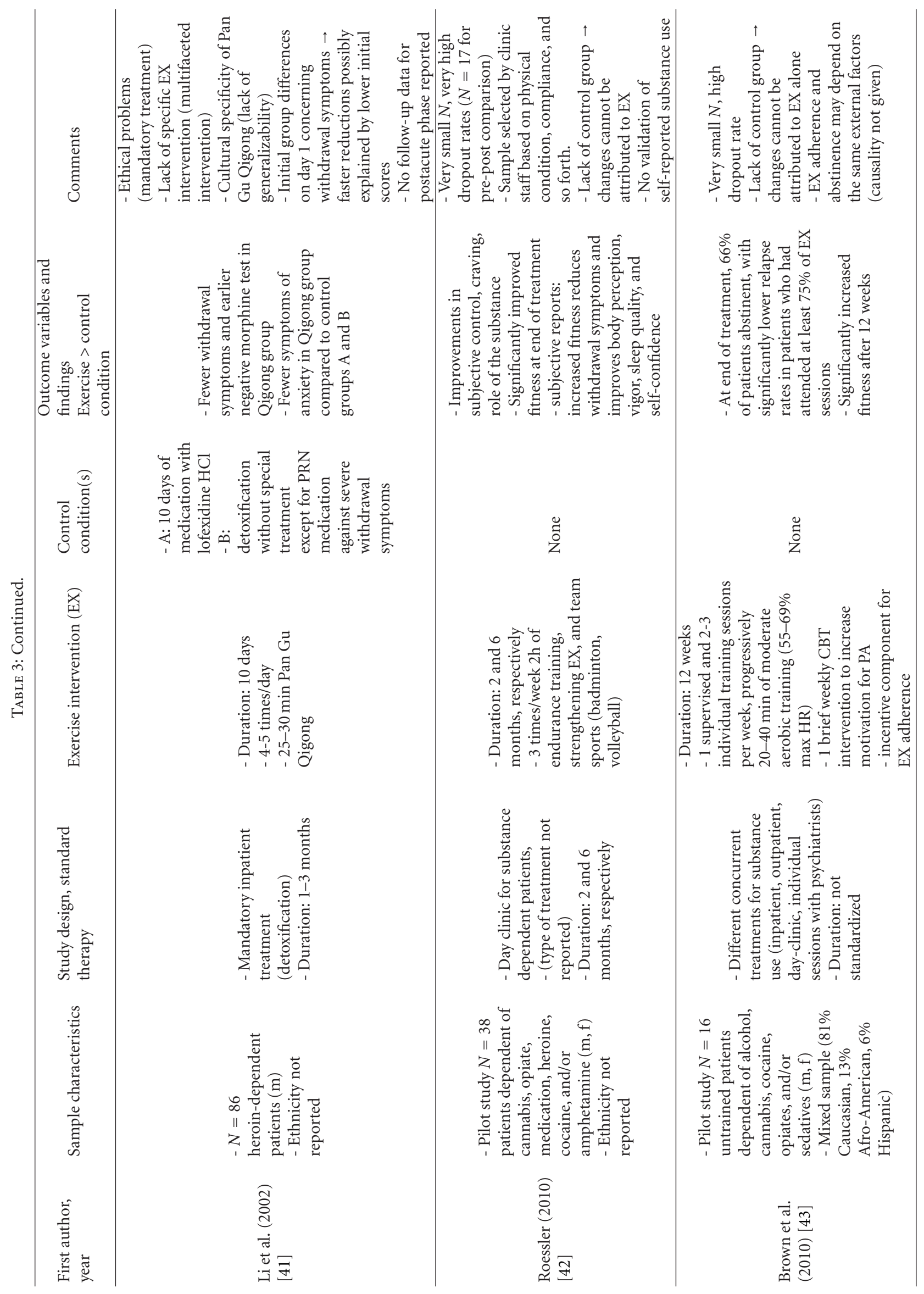




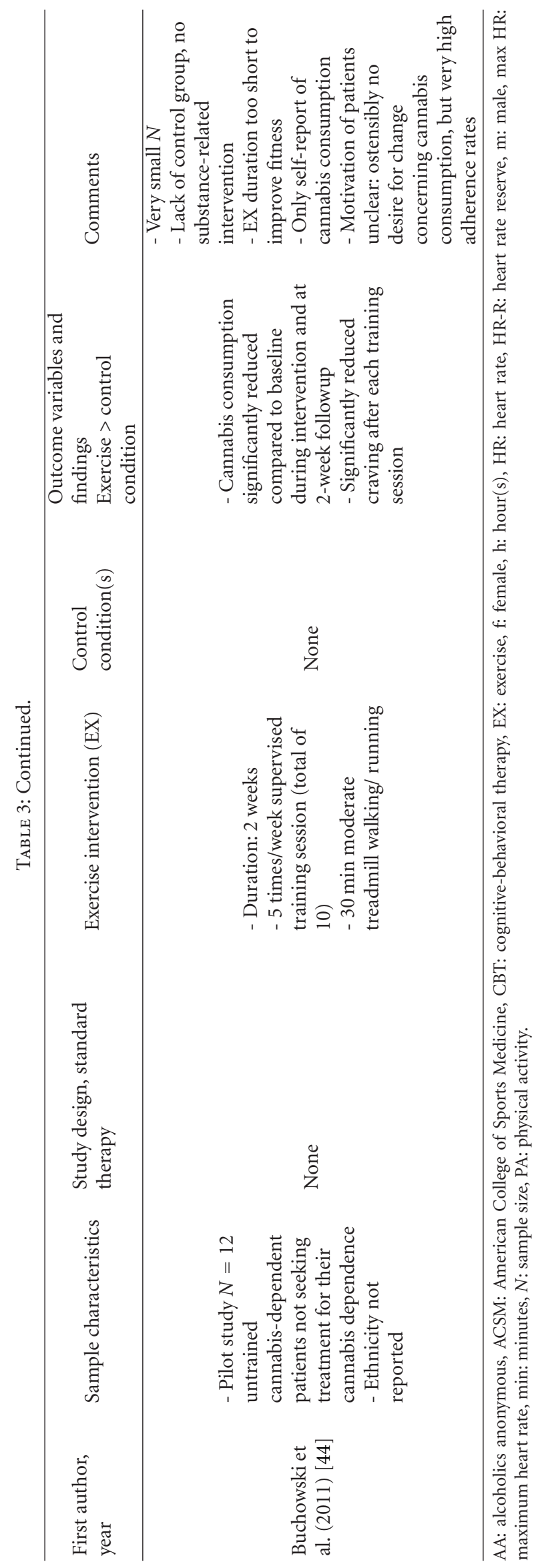


Fitness increases were reported in three studies [37, 42, $43]$, whereas the other studies did either not report [38, 40, $41,44]$ or find [39] significant changes in fitness.

All studies suffer from severe methodological limitations which constrain possible conclusions. Only two studies included control groups $[38,41]$, whereas two studies performed post hoc classifications between improvers and nonimprovers [37, 40], and four studies [39, 42-44] did not employ control conditions at all.

Sample sizes were very small [39, 40, 42-44] or contained unequal group sizes [38] in six studies, and most studies did not perform intention-to-treat analyses to correct for the high number of dropouts.

The study participants were mostly in the postacute phase after detoxification, except for the study by Li et al. [41]. Three studies did not specify the patients' diagnoses $[39,40]$ or included subclinical participants [37]. Furthermore, two studies included culture-specific interventions that were no pure EX interventions $[38,41]$ which hampers generalizability. In three studies [37, 39, 41], group differences concerning specific outcome variables were found already at the beginning of the study, partly explaining group differences at the end of treatment. Finally, self-reported substance use was not chemically validated in three studies $[37,42,44]$.

In summary, evidence is very weak concerning the efficacy of EX as an adjunct therapy in the treatment of illicit drug abuse/dependence. The studies published so far are not methodologically sound and generalizable. Therefore, only a few preliminary conclusions can be drawn pointing towards unspecific benefits of EX, given a certain duration and training intensity of the EX intervention. Well-designed studies using adequate sample sizes and control groups are needed to determine if EX programs are effective for treating SUD and, if so, under which conditions.

\section{Potential Mechanisms}

A couple of mechanisms are discussed when arguing for a beneficial role of EX intervention in psychiatric disorders and especially in SUD. However, most of these mechanisms have not directly been investigated in human SUD population. Therefore, conclusions for mechanisms can cautiously be drawn from animal studies and studies in other human populations, but their translation to SUDs remains speculative at present. Two reviews listed some of these potential mechanisms for alcohol use disorders $[54,55]$.

4.1. Neurochemical Alterations by EX. In alcohol-dependent patients, dysfunctions of dopaminergic, glutamatergic, and opioidergic neurotransmission have been linked to craving and relapse [56]. A large number of animal studies reported acute and chronic EX-induced alterations in different transmitter systems, by modifying transmitter release, reuptake, turnover, or receptor density and sensitivity, respectively. In humans, EX-induced downregulation of postsynaptic serotonin $5-\mathrm{HT}_{2} \mathrm{C}$ in panic patients [57] and reductions in prefrontal and limbic/paralimbic opioid receptor availability [58] have been reported. Furthermore, endurance training was shown to induce BDNF secretion [59], which may be linked to neuroprotection and plasticity.

4.2. Reduction of Acute Craving. Acute craving for the substance of abuse is a prominent factor of relapse [60]. At least in smoking cessation, there is evidence that EX interventions can acutely downregulate craving and withdrawal-related negative mood [19] (see also Section 3.1).

4.3. Endogenous Reward. Many SUD patients know positive, relaxed states only in conjunction with substance consumption. EX can induce pleasurable states by changes in neurotransmission (see above), which can be experienced as an internal reward stimulus [61].

4.4. Mood Regulation. Negative mood, stress, anxiety, and depressions are associated with a higher risk of relapse [62]. A number of reviews (e.g., [63]) concluded that EX can improve mood and well-being and that this effect is persistent up to 3-4 hours after about of EX [64]. It seems that different types of EX (aerobic or anaerobic) have the ability to improve mood, as long as they are not too intense and competitive, which can in turn worsen negative affect [65].

4.5. Reduction of Anxious and Depressive Symptoms. Depression is one of the most prevalent disorders in SUD, and depression is a negative predictor for treatment outcome [66].

Numerous studies supported the effectiveness of EX as a long-term intervention for anxiety and depressive disorders [67], showing that both anaerobic and aerobic trainings are in principle eligible, provided a training duration of approximately 9 weeks [63]. However, evidence is mixed with regard to the optimal intensity - some studies found lightto-moderate EX to be the most effective, others reported the largest effects at higher training intensities.

Finally, it remains controversial whether antidepressant and anxiolytic effects are specific for EX or whether unspecific effects such as therapeutic contact, engaging in health behavior, and social appreciation are mechanisms of action [65].

4.6. Stress Reactivity. Subjective stress is a factor often reported to be involved in relapse [62]. Several studies demonstrated that EX can act protectively against everyday-stress [68] and that the stress reaction to a psychosocial stressor is reduced in trained compared to untrained healthy subjects [69]. Also, a single bout of moderate EX was resported to buffer the stress reponse in untrained women [70].

4.7. Group Activity and Social Support. A social network that is not primarily related to substance consumption is often hypothesized to be a key factor of relapse prevention. Group EX may help to improve communication skills, conflict management, and frustration tolerance $[55,71]$.

4.8. Coping. Substance use can be interpreted as a maladaptive coping strategy to handle stressful, unpleasant, and 
difficult situations. In this regard, EX has been proposed to broaden the repertoire of possible behaviors and to provide alternative coping strategies for emotion regulation [72].

4.9. Maladaptive Cognitions and Self-Efficacy. Self-efficacy is reduced in many SUD patients who repeatedly experience control loss with regard to their consumption behavior. Some authors assume that supervised training can increase body-related self-efficacy by individual dosage and selfpaced progression [73]. However, it remains unclear if these changes generalize to other domains and generally increase self-esteem and reduce expectations of failure.

\section{Conclusion and Future Directions}

The above-cited studies, especially in the field of nicotine abuse/dependence, provide some evidence for positive treatment effects that can be achieved using EX interventions.

Nevertheless, it becomes obvious that evidence is very sparse with regard to alcohol and illicit drugs. Given the self-evident presence of EX programs as an integral part of almost every rehabilitation facility, it has to be pointed out that, so far, no methodologically firm studies are present to verify the long-term benefits of EX interventions with regard to craving, abstinence, relapse, and other psychological variables. Although beneficial effects induced by EX are theoretically plausible, clinically admitted, and highly intuitive, well-designed studies need to be conducted to empirically corroborate these assumptions. Future studies should report effect sizes in order to make EX effects comparable to other active treatments, such as pharmacological or psychotherapeutic interventions.

Generally, patients with poor physical condition are often excluded from studies or drop out early. In the future, more emphasis should be put on the question about (a) how patients with poor physical health can be included into EX programs and (b) how physical health changes moderate SUD-related therapy outcomes.

In the field of medication abuse, amphetamines, and synthetic drugs, no studies have been published so far.

Some further questions are of particular interest.

(i) Which mechanisms of action are particularly important in SUD patients?

(ii) Is there a linear (or curvilinear) dose-response relationship of EX and therapy outcome?

(iii) What is the minimal duration and intensity of an efficient EX program?

(iv) Which types of EX are the most effective, and how is the type of effective EX related to the patients' characteristics and cultural background?

(v) Which roles do factors like indoors versus outdoors, individual versus group EX, supervised versus nonsupervised training play?

(vi) Does an effective EX intervention necessarily require fitness increases? (vii) How can patients be motivated to adhere and continue EX programs?

\section{References}

[1] H. U. Wittchen, F. Jacobi, J. Rehm et al., "The size and burden of mental disorders and other disorders of the brain in Europe 2010," European Neuropsychopharmacology, vol. 21, no. 9, pp. 655-679, 2011.

[2] R. D. Goodwin, "Association between physical activity and mental disorders among adults in the United States," Preventive Medicine, vol. 36, no. 6, pp. 698-703, 2003.

[3] A. Ströhle, M. Höfler, H. Pfister et al., "Physical activity and prevalence and incidence of mental disorders in adolescents and young adults," Psychological Medicine, vol. 37, no. 11, pp. 1657-1666, 2007.

[4] T. Korhonen, U. M. Kujala, R. J. Rose, and J. Kaprio, "Physical activity in adolescence as a predictor of alcohol and illicit drug use in early adulthood: a longitudinal population-based twin study," Twin Research and Human Genetics, vol. 12, no. 3, pp. 261-268, 2009.

[5] G. E. Mead, W. Morley, P. Campbell, C. A. Greig, M. McMurdo, and D. A. Lawlor, "Exercise for depression," Cochrane Database of Systematic Reviews, no. 3, Article ID CD004366, 2009.

[6] A. Broocks, B. Bandelow, G. Pekrun et al., "Comparison of aerobic exercise, clomipramine, and placebo in the treatment of panic disorder," American Journal of Psychiatry, vol. 155, no. 5, pp. 603-609, 1998.

[7] D. Merom, P. Phongsavan, R. Wagner et al., "Promoting walking as an adjunct intervention to group cognitive behavioral therapy for anxiety disorders-A pilot group randomized trial," Journal of Anxiety Disorders, vol. 22, no. 6, pp. 959-968, 2008.

[8] B. M. Wipfli, C. D. Rethorst, and D. M. Landers, "The anxiolytic effects of exercise: a meta-analysis of randomized trials and dose-response analysis," Journal of Sport and Exercise Psychology, vol. 30, no. 4, pp. 392-410, 2008.

[9] F. Chacón, F. Mora, A. Gervás-Ríos, and I. Gilaberte, "Efficacy of lifestyle interventions in physical health management of patients with severe mental illness," Annals of General Psychiatry, vol. 10, article 22, 2011.

[10] W. C. Lin, J. Zhang, G. Y. Leung, and R. E. Clark, "Chronic physical conditions in older adults with mental illness and/ or substance use disorders," Journal of the American Geriatrics Society, vol. 59, no. 10, pp. 1913-1921, 2011.

[11] J. S. Hill, "Effect of a program of aerobic exercise on the smoking behaviour of a group of adult volunteers," Canadian Journal of Public Health, vol. 76, no. 3, pp. 183-186, 1985.

[12] P. O. Russell, L. H. Epstein, J. J. Johnston, D. R. Block, and E. Blair, "The effects of physical activity as maintenance for smoking cessation," Addictive Behaviors, vol. 13, no. 2, pp. 215-218, 1988.

[13] C. B. Taylor, N. Houston-Miller, W. L. Haskell, and R. F. Debusk, "Smoking cessation after acute myocardial infarction: the effects of exercise training," Addictive Behaviors, vol. 13, no. 4, pp. 331-335, 1988.

[14] B. H. Marcus, A. E. Albrecht, R. S. Niaura, D. B. Abrams, and P. D. Thompson, "Usefulness of physical exercise for maintaining smoking cessation in women," American Journal of Cardiology, vol. 68, no. 4, pp. 406-407, 1991.

[15] R. D. Hill, M. Rigdon, and S. Johnson, "Behavioral smoking cessation treatment for older chronic smokers," Behavior Therapy, vol. 24, no. 2, pp. 321-329, 1993. 
[16] B. H. Marcus, A. E. Albrecht, R. S. Niaura et al., "Exercise enhances the maintenance of smoking cessation in women," Addictive Behaviors, vol. 20, no. 1, pp. 87-92, 1995.

[17] J. E. Martin, K. J. Calfas, C. A. Patten et al., "Prospective evaluation of three smoking interventions in 205 recovering alcoholics: one-year results of project SCRAP-tobacco," Journal of Consulting and Clinical Psychology, vol. 65, no. 1, pp. 190-194, 1997.

[18] B. H. Marcus, A. E. Albrecht, T. K. King et al., "The efficacy of exercise as an aid for smoking cessation in women: a randomized controlled trial," Archives of Internal Medicine, vol. 159, no. 11, pp. 1229-1234, 1999.

[19] B. C. Bock, B. H. Marcus, T. K. King, B. Borrelli, and M. R. Roberts, "Exercise effects on withdrawal and mood among women attempting smoking cessation," Addictive Behaviors, vol. 24, no. 3, pp. 399-410, 1999.

[20] M. Ussher, R. West, A. McEwen, A. Taylor, and A. Steptoe, "Efficacy of exercise counselling as an aid for smoking cessation: a randomized controlled trial," Addiction, vol. 98, no. 4, pp. 523-532, 2003.

[21] B. H. Marcus, B. A. Lewis, J. Hogan et al., "The efficacy of moderate intensity exercise as an aid for smoking cessation in women: a randomized controlled trial," Nicotine and Tobacco Research, vol. 7, no. 6, pp. 871-880, 2005.

[22] H. Prapavessis, L. Cameron, J. C. Baldi et al., "The effects of exercise and nicotine replacement therapy on smoking rates in women," Addictive Behaviors, vol. 32, no. 7, pp. 1416-1432, 2007.

[23] S. E. Chaney and S. Sheriff, "Weight gain among women during smoking cessation: testing the effects of a multifaceted program," AAOHN Journal, vol. 56, no. 3, pp. 99-105, 2008.

[24] T. Kinnunen, R. F. Leeman, T. Korhonen et al., "Exercise as an adjunct to nicotine gum in treating tobacco dependence among women," Nicotine and Tobacco Research, vol. 10, no. 4, pp. 689-703, 2008.

[25] J. J. Prochaska, S. M. Hall, G. Humfleet et al., "Physical activity as a strategy for maintaining tobacco abstinence: a randomized trial," Preventive Medicine, vol. 47, no. 2, pp. 215 220, 2008.

[26] D. M. Williams, J. A. Whiteley, S. Dunsiger et al., "Moderate intensity exercise as an adjunct to standard smoking cessation treatment for women: a pilot study," Psychology of Addictive Behaviors, vol. 24, no. 2, pp. 349-354, 2010.

[27] K. S. Vickers, C. A. Patten, B. A. Lewis et al., "Feasibility of an exercise counseling intervention for depressed women smokers," Nicotine and Tobacco Research, vol. 11, no. 8, pp. 985-995, 2009.

[28] V. Gary and D. Guthrie, "The effect of jogging on physical fitness and self-concept in hospitalized alcoholics," Quarterly Journal of Studies on Alcohol, vol. 33, no. 4, pp. 1073-1078, 1972.

[29] A. Frankel and J. Murphy, "Physical fitness and personality in alcoholism. Canonical analysis of measures before and after treatment," Quarterly Journal of Studies on Alcohol, vol. 35, no. 4 A, pp. 1272-1278, 1974.

[30] D. Sinyor, T. Brown, L. Rostant, and P. Seraganian, "The role of a physical fitness program in the treatment of alcoholism," Journal of Studies on Alcohol, vol. 43, no. 3, pp. 380-386, 1982.

[31] A. Weber, "Running as treatment for hospitalized alcoholics: an experimental approach," Suchtgefahren, vol. 30, no. 3, pp. 160-167, 1984.

[32] T. J. Murphy, R. R. Pagano, and G. A. Marlatt, "Lifestyle modification with heavy alcohol drinkers: effects of aerobic exercise and meditation," Addictive Behaviors, vol. 11, no. 2, pp. 175-186, 1986.

[33] J. Palmer, N. Vacc, and J. Epstein, "Adult inpatient alcoholics: physical exercise as a treatment intervention," Journal of Studies on Alcohol, vol. 49, no. 5, pp. 418-421, 1988.

[34] M. E. Donaghy, The Investigation of Exercise as an Adjunct to the Treatment and Rehabilitation of the Problem Drinker, University of Glasgow, Glasgow, UK, 1977.

[35] R. Ermalinski, P. G. Hanson, B. Lubin, J. I. Thornby, and P. A. Nahormek, "Impact of a body-mind treatment component on alcoholic inpatients," Journal of Psychosocial Nursing and Mental Health Services, vol. 35, no. 7, pp. 39-45, 1997.

[36] R. A. Brown, A. M. Abrantes, J. P. Read et al., "Aerobic exercise for alcohol recovery: rationale, program description, and preliminary findings," Behavior Modification, vol. 33, no. 2, pp. 220-249, 2009.

[37] T. R. Collingwood, R. Reynolds, H. W. Kohl, W. Smith, and S. Sloan, "Physical fitness effects on substance abuse risk factors and use patterns," Journal of Drug Education, vol. 21, no. 1, pp. 73-84, 1991.

[38] T. A. Burling, A. L. Seidner, D. Robbins-Sisco, A. Krinsky, and S. B. Hanser, "Batter up! Relapse prevention for homeless veteran substance abusers via softball team participation," Journal of Substance Abuse, vol. 4, no. 4, pp. 407-413, 1992.

[39] J. A. Palmer, L. K. Palmer, K. Michiels, and B. Thigpen, "Effects of type of exercise on depression in recovering substance abusers," Perceptual and Motor Skills, vol. 80, no. 2, pp. 523-530, 1995.

[40] D. J. Williams, "Exercise and substance abuse treatment: predicting programm completion," Corrections Compendium, vol. 25 , no. 25 , pp. $4-7,2000$.

[41] M. Li, K. Chen, and Z. Mo, "Use of qigong therapy in the detoxification of heroin addicts," Alternative Therapies in Health and Medicine, vol. 8, no. 1, pp. 50-59, 2002.

[42] K. K. Roessler, "Exercise treatment for drug abuse-a danish pilot study," Scandinavian Journal of Public Health, vol. 38, no. 6, pp. 664-669, 2010.

[43] R. A. Brown, A. M. Abrantes, J. P. Read et al., "A pilot study of aerobic exercise as an adjunctive treatment for drug dependence," Mental Health and Physical Activity, vol. 3, no. 1, pp. 27-34, 2010.

[44] M. S. Buchowski, N. N. Meade, E. Charboneau et al., "Aerobic exercise training reduces cannabis craving and use in nontreatment seeking cannabis-dependent adults," PLoS ONE, vol. 6, no. 3, Article ID e17465, 2011.

[45] S. A. Schroeder and C. D. Morris, "Confronting a neglected epidemic: tobacco cessation for persons with mental illnesses and substance abuse problems," Annual Review of Public Health, vol. 31, pp. 297-314, 2010.

[46] J. R. Hughes, J. Keely, and S. Naud, "Shape of the relapse curve and long-term abstinence among untreated smokers," Addiction, vol. 99, no. 1, pp. 29-38, 2004.

[47] A. Batra, "Treatment of tobacco dependence," Deutsches Arzteblatt, vol. 108, no. 33, pp. 555-564, 2011.

[48] A. H. Taylor, M. H. Ussher, and G. Faulkner, "The acute effects of exercise on cigarette cravings, withdrawal symptoms, affect and smoking behaviour: a systematic review," Addiction, vol. 102, no. 4, pp. 534-543, 2007.

[49] M. H. Ussher, A. Taylor, and G. Faulkner, "Exercise interventions for smoking cessation," Cochrane Database of Systematic Reviews, no. 4, p. CD002295, 2008.

[50] P. Haber et al., Guidelines for the Treatment of Alcohol Problems, The University of Sydney, Sydney, Australia, 2009. 
[51] T. Kienast and A. Heinz, "Therapy and supportive care of alcoholics: guidelines for practitioners," Digestive Diseases, vol. 23, no. 3-4, pp. 304-309, 2006.

[52] M. Ussher, A. K. Sampuran, R. Doshi, R. West, and D. C. Drummond, "Acute effect of a brief bout of exercise on alcohol urges," Addiction, vol. 99, no. 12, pp. 1542-1547, 2004.

[53] J. P. Read, R. A. Brown, B. H. Marcus et al., "Exercise attitudes and behaviors among persons in treatment for alcohol use disorders," Journal of Substance Abuse Treatment, vol. 21, no. 4, pp. 199-206, 2001.

[54] R. A. Brown, A. M. Abrantes, J. P. Read et al., "Aerobic exercise for alcohol recovery: rationale, program description, and preliminary findings," Behavior Modification, vol. 33, no. 2, pp. 220-249, 2009.

[55] J. P. Read and R. A. Brown, "The role of physical exercise in alcoholism treatment and recovery," Professional Psychology: Research and Practice, vol. 34, no. 1, pp. 49-56, 2003.

[56] A. Heinz, A. Beck, S. M. Grüsser, A. A. Grace, and J. Wrase, "Identifying the neural circuitry of alcohol craving and relapse vulnerability," Addiction Biology, vol. 14, no. 1, pp. 108-118, 2009.

[57] A. Broocks, T. Meyer, M. Opitz et al., "5-HT1A responsivity in patients with panic disorder before and after treatment with aerobic exercise, clomipramine or placebo," European Neuropsychopharmacology, vol. 13, no. 3, pp. 153-164, 2003.

[58] H. Boecker, T. Sprenger, M. E. Spilker et al., "The runner's high: opioidergic mechanisms in the human brain," Cerebral Cortex, vol. 18, no. 11, pp. 2523-2531, 2008.

[59] T. Seifert, P. Brassard, M. Wissenberg et al., "Endurance training enhances BDNF release from the human brain," American Journal of Physiology-Regulatory Integrative and Comparative Physiology, vol. 298, no. 2, pp. R372-R377, 2010.

[60] A. Heinz, "Dopaminergic dysfunction in alcoholism and schizophrenia-psychopathological and behavioral correlates," European Psychiatry, vol. 17, no. 1, pp. 9-16, 2002.

[61] S. Brené, A. Bjørnebekk, E. Åberg, A. A. Mathé, L. Olson, and M. Werme, "Running is rewarding and antidepressive," Physiology and Behavior, vol. 92, no. 1-2, pp. 136-140, 2007.

[62] K. D. Brownell, G. A. Marlatt, E. Lichtenstein, and G. T. Wilson, "Understanding and preventing relapse," American Psychologist, vol. 41, no. 7, pp. 765-782, 1986.

[63] D. Scully, "Physical exercise and psychological well being: a critical review," British Journal of Sports Medicine, vol. 32, no. 2, pp. 111-120, 1998.

[64] R. R. Yeung, "The acute effects of exercise on mood state," Journal of Psychosomatic Research, vol. 40, no. 2, pp. 123-141, 1996.

[65] P. Salmon, "Effects of physical exercise on anxiety, depression, and sensitivity to stress: a unifying theory," Clinical Psychology Review, vol. 21, no. 1, pp. 33-61, 2001.

[66] D. C. Hodgins, N. El-Guebaly, S. Armstrong, and M. Dufour, "Implications of depression on outcome from alcohol dependence: a 3-year prospective follow-up," Alcoholism: Clinical and Experimental Research, vol. 23, no. 1, pp. 151-157, 1999.

[67] A. Ströhle, "Physical activity, exercise, depression and anxiety disorders," Journal of Neural Transmission, vol. 116, no. 6, pp. 777-784, 2009.

[68] A. Steptoe, J. Kimbell, and P. Basford, "Exercise and the experience and appraisal of daily stressors: a naturalistic study," Journal of Behavioral Medicine, vol. 21, no. 4, pp. 363-374, 1998.

[69] U. Rimmele, B. C. Zellweger, B. Marti et al., "Trained men show lower cortisol, heart rate and psychological responses to psychosocial stress compared with untrained men," Psychoneuroendocrinology, vol. 32, no. 6, pp. 627-635, 2007.

[70] W. J. Rejeski, A. Thompson, P. H. Brubaker, and H. S. Miller, "Acute exercise: buffering psychosocial stress responses in women," Health Psychology, vol. 11, no. 6, pp. 355-362, 1992.

[71] K. Humphreys, R. H. Moos, and J. W. Finney, "Two pathways out of drinking problems without professional treatment," Addictive Behaviors, vol. 20, no. 4, pp. 427-441, 1995.

[72] M. L. Hobson and W. J. Rejeski, "Does the dose of acute exercise mediate psychophysiological responses to mental stress," Journal of Sport \& Exercise Psychology, vol. 15, no. 1, pp. 77-87, 1993.

[73] K. Lexington, "The Atwood Hall Health Promotion Program, Federal Medical Center, Lexington, KY: effects on drug-involved federal offenders," Journal of Substance Abuse Treatment, vol. 12, no. 1, pp. 43-48, 1995. 


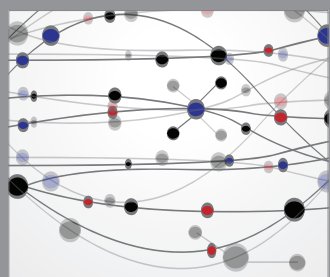

The Scientific World Journal
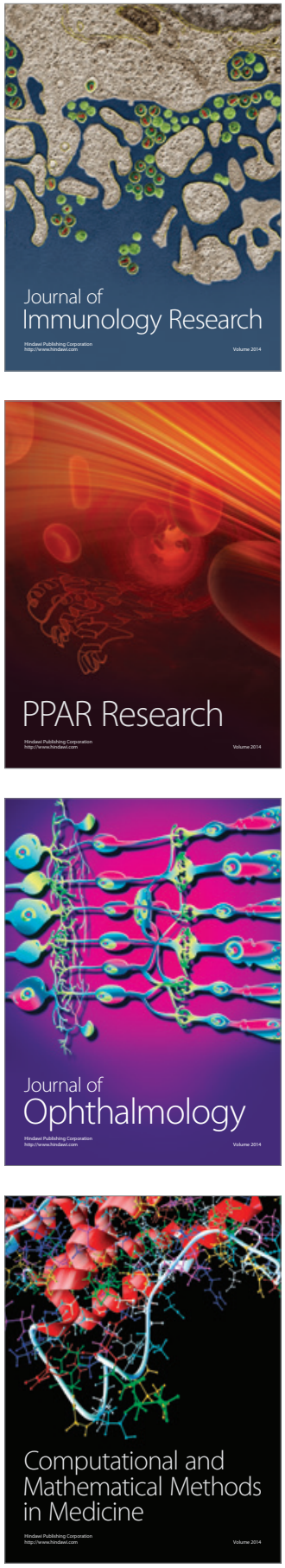

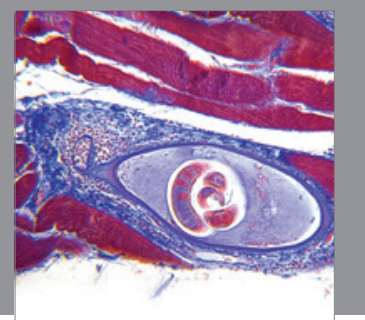

Gastroenterology

Research and Practice
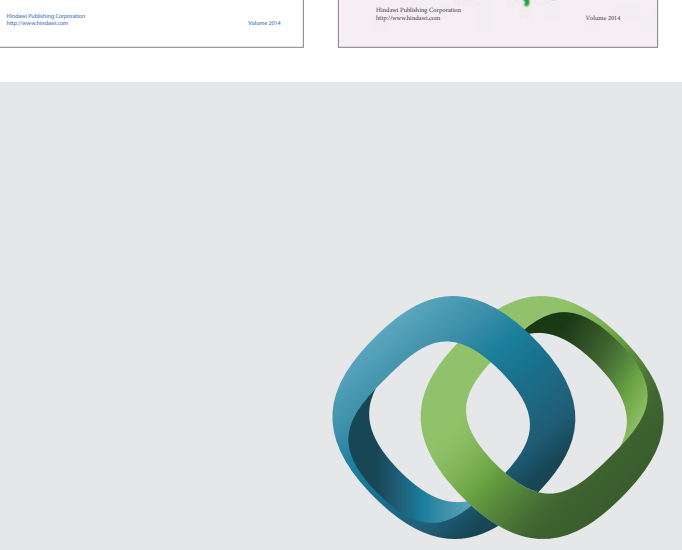

\section{Hindawi}

Submit your manuscripts at

http://www.hindawi.com
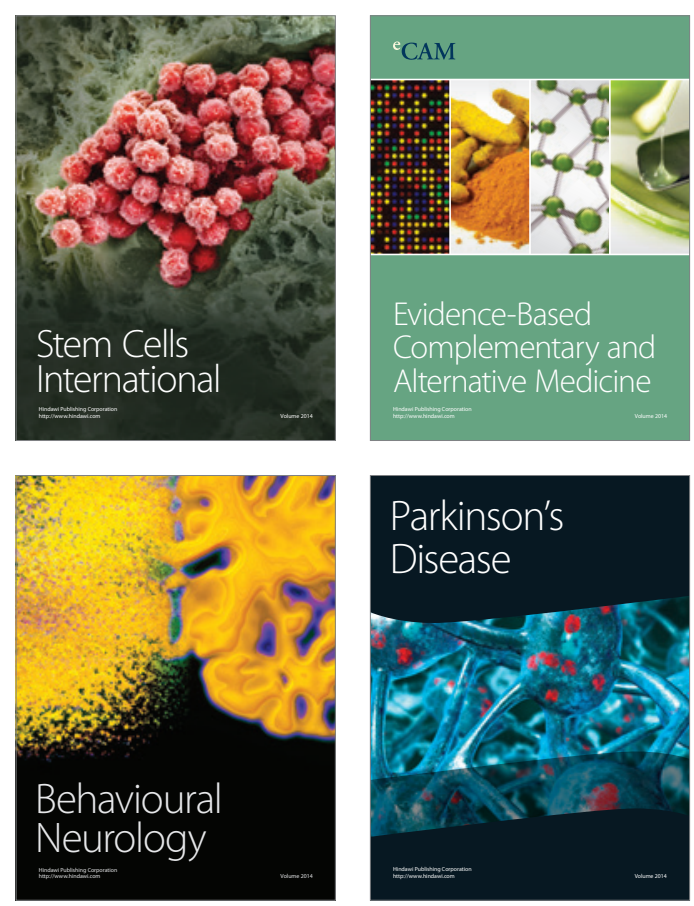

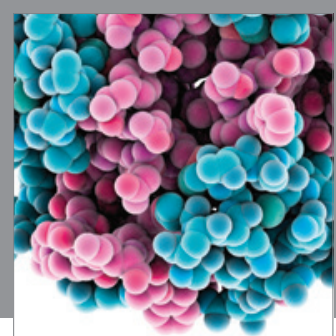

Journal of
Diabetes Research

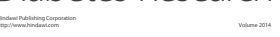

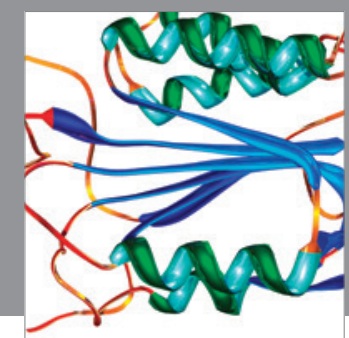

Disease Markers
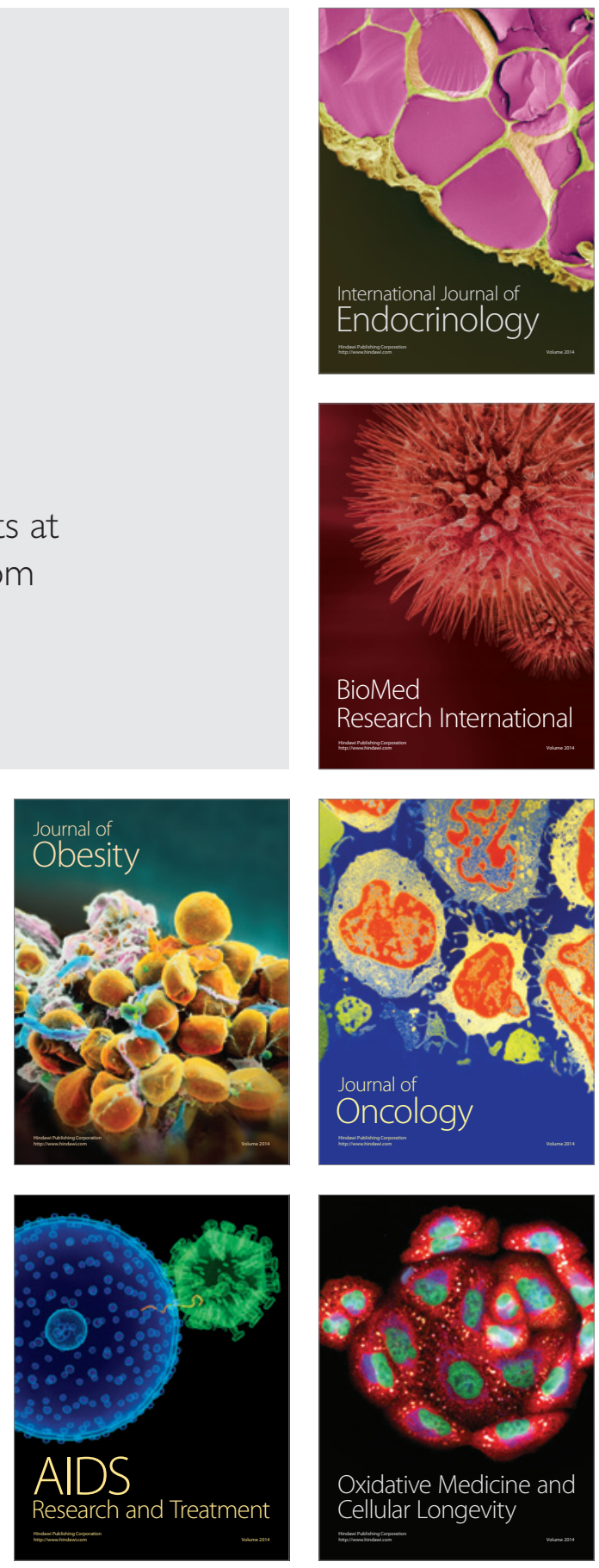